

\title{
Heterogeneity, convergence and imbalances in the Euro area
}

Stéphane Auray, Aurélien Eyquem

\section{To cite this version:}

Stéphane Auray, Aurélien Eyquem. Heterogeneity, convergence and imbalances in the Euro area. Revue de l'OFCE, 2021, VARIA, 3 (173), pp.117-152. hal-03394885

\section{HAL Id: hal-03394885 \\ https://hal-sciencespo.archives-ouvertes.fr/hal-03394885}

Submitted on 22 Oct 2021

HAL is a multi-disciplinary open access archive for the deposit and dissemination of scientific research documents, whether they are published or not. The documents may come from teaching and research institutions in France or abroad, or from public or private research centers.
L'archive ouverte pluridisciplinaire HAL, est destinée au dépôt et à la diffusion de documents scientifiques de niveau recherche, publiés ou non, émanant des établissements d'enseignement et de recherche français ou étrangers, des laboratoires publics ou privés. 


\title{
HETEROGENEITY, CONVERGENCE AND IMBALANCES IN THE EURO AREA
}

\author{
Stéphane Auray \\ CREST-Ensai, ULCO \\ Aurélien Eyquem \\ Université Lumière Lyon 2, Institut Universitaire de France
}

The inception of the euro allowed countries from the periphery to experience a large fall in the cost of borrowing. Lower nominal rates were only partially offset by lower inflation rates. We rationalize this real interest rate reversal using a two-region model of a monetary union where, consistently with real interest rate data, discount factors are initially heterogeneous, leading the periphery to be borrowing-constrained. We model the inception of the euro as a partial convergence process in inflation rates and a slow rise in the discount factor of the periphery, relaxing the borrowing constraint. This simple set-up accounts for the bulk of post-euro fluctuations in both regions. In particular, it replicates very well the observed joint dynamics of current accounts and terms of trade.

Keywords: Monetary union, inflation convergence, current account imbalances, borrowing constraints.

\section{Introduction}

The inception of the euro and its consequences have been the subject of many studies in the literature. The subject has gained a dramatic importance once European countries were hit by the 2009 crisis. This paper proposes a new theoretical perspective on the origins of the euro area imbalances in the aftermath of the inception of the euro, with a focus on the pre-2009 period.

A key question of the literature is the source of intra-EMU imbalances that were observed after the common currency was adopted. 
Those are measured by current account surpluses in core countries, deficits in the periphery, as well as real exchange rate divergence. Among the explanations proposed so far, we find the growth catch-up assumption coupled with financial integration - perspectives of future growth in peripheric countries that started with a lower level of GDP per capita borrow from abroad to sustain investment (Blanchard and Giavazzi, 2002). We also find various sources of capital misallocation: credit market imperfections (Sy (2016)), size-dependent borrowing constraints at the firm level (Gopinath, Kalemli ; Ozcan, Karabarbounis, and Villegas-Sanchez, 2017), bubbles (Lourenço and Rodrigues (2015)), heterogeneity in the banking sector (Ozhan (2020)), generating changes in competitiveness and current account deficits. The structure of trade outside the euro area has also been invoked (Chen, Milesi-Ferretti, and Tressel, 2012). More recently, Siena (2021) uses an estimated DGSE model to show that the Euro triggered an anticipation of narrowing interest rate spreads in the future and that anticipation effects matter in the building-up of imbalances.

In this paper, we show that a relatively simple two-region model of a monetary union matches the data pretty well through a main driver: a decreasing real interest rates in the periphery along with a relatively constant real rate in the core region. ${ }^{1}$ In the data, this movement appears to be driven by two forces: the advent of a much smaller nominal rate in the periphery - the rate applied by the ECB simply followed the pre-euro level applied by central banks in the core region - and a partial convergence in inflation rates (see Section 2 on Figure 1). We introduce pre-euro heterogeneity in real rates (and hence discount factors) through a simple borrowing constraint by which households in the periphery can not borrow as much as desired given the wedge between the subjective real interest rate and the effective real rate.

We rationalize the inception of the euro as a partial convergence process in inflation rates along with a slow-moving discount factor shock in the peripheric region. This minimal set of driving forces already produces effects that are qualitatively consistent with the observed post-euro dynamics in both regions, and of the right order of magnitude. It produces a large investment boom in the periphery,

1. Our model is relatively close to Rubio (2018), although we use it for a different purpose and in a different context. 
associated with a large and persistent current account deficit and a fall in competitiveness - a rise in the relative price of traded goods. Adding TFP and government spending shocks as additional drivers helps improve the fit with the data. Our main conclusion however is that the bulk of macroeconomic dynamics observed after the euro is the equilibrium result of the interaction between relaxed borrowing constraints in the periphery and the adoption of a monetary policy set-up featuring lower nominal rates in the periphery and partial inflation convergence. Given the structural heterogeneity that characterized the euro area before the euro, the building-up of imbalances within the euro area emerges as an equilibrium outcome.

The full model features two regions, capital accumulation, incomplete international financial markets, trade in final goods, sticky prices and a constraint on foreign borrowing. The purpose of the latter is mostly to allow for heterogeneity in subjective discount factors in the initial steady state, as it becomes and remains slack as soon as the euro is introduced. Additional sources of ex-ante heterogeneity are considered: region size, the relative levels of TFP, the shares of government spending in GDP, and the steady-state levels of inflation. Within this framework, we introduce a convergence process that captures key features of the post-euro period: a stability of the union-wide nominal interest rate - aligned on the pre-euro levels of the core region, a partial convergence of steady-state inflation rates and a slow rise in the subjective discount factor of households in the periphery - to be consistent with post-transition levels of the nominal interest rate and the inflation rate. These convergence processes are calibrated on observed pre- and post-EMU data both for the core region and for the periphery.

We simulate the model with the convergence processes along with the observed levels TFP and shares of government spending in GDP. The model fits quite well the observed dynamics of output, investment, consumption, current account and terms of trade. In particular, the dynamics of private investment is correctly reproduced in both regions. The dynamics of GDP in the core region, the joint dynamics of current accounts and the rise in terms of trade - i.e. the loss of competitiveness of the periphery - are also particularly well accounted for. Removing TFP and government spending shocks further suggests that the results are quantitatively different but qualitatively similar, as most features observed in the data before 2008 are qualitatively preserved. In addi- 
tion, a counterfactual experiment featuring a full convergence process in inflation rates suggests that the partial nature of inflation convergence plays a crucial role. More especially, had inflation in the periphery converged to the steady-state value of the core region, current account imbalances would have been substantially reduced and the deterioration of competitiveness in the periphery would have been close to zero.

Our baseline simulation also accounts for the bulk of fluctuations observed in the core region after 2008. However, fluctuations observed in the periphery after 2008 and 2011 are not well reproduced, as we abstract from several key ingredients such as banking frictions or sovereign default risk. Our results suggest that the bulk of post-EMU imbalances are the result of the inception of the euro that (i) lowered nominal rates in the periphery and (ii) did not foster a full convergence of inflation rates, in a context of ex-ante heterogeneity in nominal interest rates and inflation rates. In other words, real interest rates were highly heterogeneous ex-ante and did not converge to a common value ex-post.

As made clear in the simple model developed to build intuition and in the sensitivity analysis, an important requirement for our model to generate imbalances must be met: the adjustment of the discount factor should be very slow. Indeed, if the discount factor is adjusting too quickly compared to the real interest rate, then the model predicts a fall in consumption rather than a rise in consumption, leading to depreciated terms of trade, i.e. an improvement of competitiveness, and trade surpluses in the periphery. Our results are however quantitatively very robust to all the other key parameters of the model.

The paper is organized as follows. Section 2 presents a set of motivating facts justifying the main assumptions of our model. A simple real model of a small open economy is presented in Section 3 to provide some intuition about the main mechanisms at play in the full model, presented in Section 4. Section 5 presents the calibration and discusses the long-run implications of the model. Section 6 presents the results of our baseline calibration, and shows the prominent role of the inflation convergence process in generating external imbalances. Section 7 conducts some robustness checks according to key parameters, and some concluding remarks are offered in Section 8. 


\section{Motivating facts}

We focus on two sub-groups of countries of the euro area 5 years before and after the inception of the euro, i.e. from 1993 to 1999 and then from 1999 to 2016. We consider 10 of the 11 countries that launched the euro, excluding Luxembourg. Greece entered in 2001 and is also excluded. The core region is made of Austria, Belgium, Finland, France, Germany and the Netherlands and accounts for roughly $65 \%$ of the GDP of the whole monetary union. The periphery includes Ireland, Italy, Portugal and Spain, and accounts for the remaining $35 \%$ of GDP of the monetary union. Figure 1 below reports two sets of facts, one regarding inflation and interest rates (panel (a) to (c)) and another regarding macroeconomic aggregates (panel (d) to (h)). For the first one, region-specific inflation rates, nominal interest rates and real interest rates are reported in levels along with their average values before and after the euro. We correct these time series from any potential global trend by deflating them with the HP-filter trend of the corresponding time series in the US. ${ }^{2}$ For the second set of variables, macroeconomic time series are reported only from 1999 onwards. They are taken in levels (for GDP, consumption, investment and terms of trade) or as a percentage of GDP, and normalized by their 1999 levels.

Regarding inflation rates (panel (a)), the data suggest a clear convergence pattern. The inflation rate falls substantially in the periphery after the euro (from $4.14 \%$ to $2.79 \%$ annually) while it remains roughly stable in the core region (from $1.93 \%$ to $2.18 \%$ annually). Prior to the euro, the nominal rate was quite high in the periphery (6.23\% annually) while much lower in the core region, around $3 \%$ (panel (b)). After the euro, both regions share the same currency and hence the same nominal rate. The latter settles at the pre-euro level of the nominal rate in the core region, around $3.2 \%$. With a roughly stable nominal rate and inflation rate, the real rate observed in the core region remains broadly unchanged (panel (c)). In the periphery however, the combination of a moderate decrease in the inflation rate and a much smaller nominal rate produces a dramatic fall in the real rate: from around $2 \%$ before the euro to $0.42 \%$ annually after the euro.

2. For example, the inflation rates of the core and peripheric regions are deflated by the normalized HP-filter trend of US inflation. We use a smoothing parameter of 1600 . We proceed similarly for the nominal interest rate series and for the real rate series, using the corresponding US time series. 
(a) Inflation rates

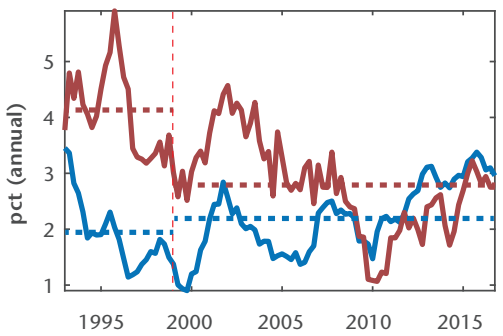

(d) GDP

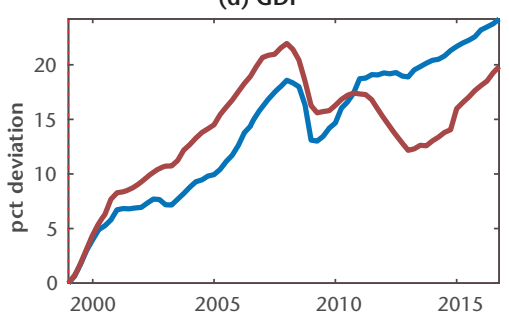

(g) Current account

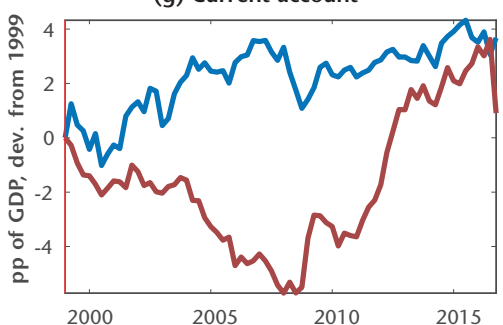

(b)Nominal interest rates

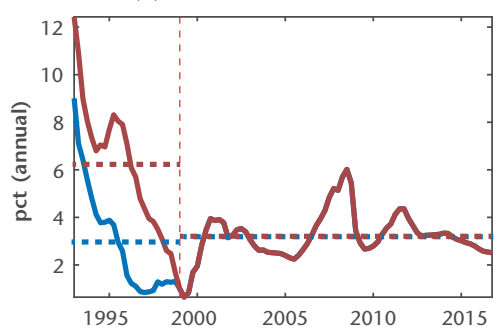

(e) Consumption

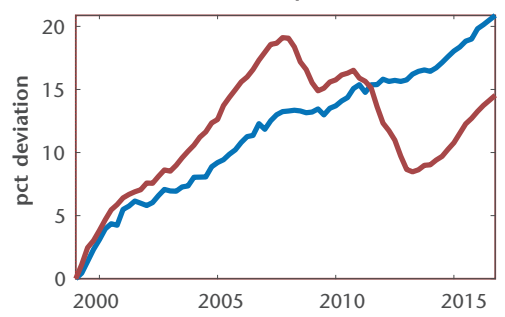

(h) Terms of trade

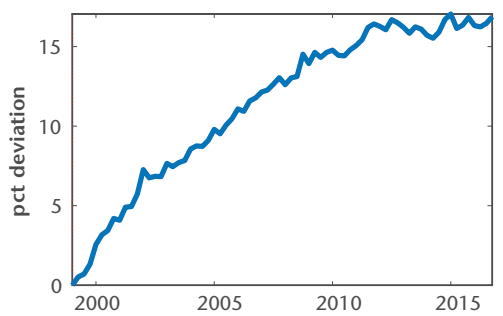

(c) Real interest rates



(f) Investment

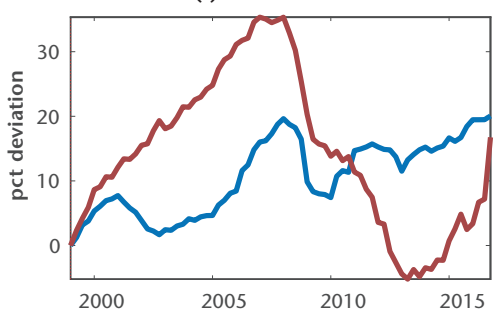

Core

- Periphery

- - - Core averages

- - - Periphery averages 
This set of facts motivates us the modeling the inception of the euro as a partial convergence process in inflation rates, along with a minor change in the interest rate target of the Central Bank. For this process to be consistent with a long-run equilibrium of the model, we consider that the (exogenous) discount factors adjust accordingly. This joint process will account for the large fall of the equilibrium real rate in the periphery after the euro was introduced. To do so, and to analyze the transition within a unified monetary-union framework, we consider a borrowing constraint that restricts the possibilities of running too negative external debt positions. We posit a difference in initial discount factors, so as to match the pre-euro equilibrium real interest rates which is enough to ensure that the borrowing constraint is biding in the region with low discount factor (and not binding in the other region). What the model adds to standard open-economy frameworks with borrowing constraints is an exogenous convergence in the discount factors, along with an exogenous shift in steady-state inflation rates, to capture the effects of the inception of a common currency.

Regarding other macroeconomic aggregates, post-euro dynamics are characterized by a boom in GDP, consumption and investment in both regions. The boom is much larger for the periphery before the 2008 Great Recession though, and reverses after. Over the whole sample, the core region is experiencing well-documented sequence of current account surpluses while the periphery experiences a series of large current-account deficits, that are dramatically reduced after the 2008 Great Recession. Last, a steady increase of the relative price of traded goods is observed in the periphery over the whole sample. In the next sections, we show that the bulk of macroeconomic trends observed in panel (d) to panel (h) can be rationalized with a relatively simple model of a two-region monetary union with trade, sticky prices, incomplete markets, and a borrowing constraint that initially binds in the periphery. Before presenting the full model, we present a simple small open economy model that is used to develop the intuition. 


\section{Intuitions from a simple model}

We start making our point using a simplified small-open economy model. The model has no capital accumulation nor nominal rigidities, and the real interest rate is exogenous. The idea is to investigate the impact of a negative real interest rate shock that releases a borrowing constraint bearing on foreign assets. The utility of households derives from consumption $c_{t}$, a stock of durables $d_{t}$ and hours worked $h_{t}$, with a lifetime welfare function

$$
E_{t}\left\{\sum_{s=t}^{\infty} \beta^{s} \log c_{t}+\chi_{d} \log d_{t}^{i}-\chi_{h} \frac{h_{t}^{1+\psi}}{1+\psi}\right\}, \beta<1
$$

that is maximized with respect to the following budget constraint

$$
c_{t}+q_{t} \Delta d_{t}+b_{t}=w_{t} h_{t}+r_{t}^{*} b_{t-1}
$$

$q_{t}$ is the relative price of durables, $\Delta$ is the first-difference operator, $b_{t}^{i}$ is the amount of international one-period bonds held by households in the small open economy that pays an exogenous real rate $r_{t}^{*}, w_{t}$ is the real wage. In addition to the budget constraint, households also face a constraint on the expected amount they can borrow from the rest of the world based on the amount of durable goods they can pledge:

$$
-r_{t}^{*} b_{t} \leq m E_{t}\left\{q_{t+1} d_{t}\right\}
$$

The main idea of this borrowing constraint is that borrowing internationally requires some form of collateral, which then potentially restricts the possibility of households to access financial markets.

Using the fact that the stock of durables is constant and normalized, i.e. $d_{t}=1$, the associated first-order conditions are:

$$
\begin{gathered}
\chi_{d} c_{t}+E_{t}\left\{m \lambda_{t} q_{t+1}+\beta \frac{c_{t}}{c_{t+1}} q_{t+1}\right\}=q_{t} \\
\chi_{h} h_{t}^{\psi} c_{t}=w_{t} \\
\beta E_{t}\left\{\frac{c_{t}}{c_{t+1}} \frac{r_{t}^{*}}{\left(1-r_{t}^{*} \lambda_{t}\right)}\right\}=1
\end{gathered}
$$

where $\lambda_{t}$ is the Lagrange multiplier associated with the borrowing constraint, normalized by the Lagrange multiplier associated to the budget constraint. Aggregate consumption is a bundle of domestic and foreign production with a unit elasticity of substitution. The price of goods produced in the small open economy is $p_{y, t}$ and that of the foreign good is $p_{y^{*}}$. A similar structure characterizes the foreign 
demands - up to the small open economy assumption. As a consequence the goods market clearing condition in the small open economy writes

$$
y_{t}=(1-\alpha) s_{t}^{-\alpha} c_{t}+\alpha s_{t}^{-1} c^{*}
$$

where $1-\alpha \leq 1$ measures the weight of local goods in the bundle, and $s_{t}=p_{y t} / p_{y^{*}}$ denotes the terms of trade. ${ }^{3}$ This equation states that production depends positively on local and foreign aggregate consumption, and that terms of trade appreciation ( $s_{t}$ goes up) generates expenditure switching effects away from local goods. In the case of our experiment, rising consumption is expected to put pressure on output and imply a rise in prices, appreciating terms of trade. In turn, this appreciation should divert some of the demand towards foreign-produced goods therefore partly offsetting the rise in domestic production.

The production sector is simplistic: a single firm competitively produces a local good using domestic labor with a linear production function $y_{t}=h_{t}$. With flexible prices this equation implies the following labor demand function: $p_{y t}=p_{t} w_{t}$, implying $w_{t}=s_{t}^{\alpha}{ }^{4}$ Using this result and the production function to substitute for hours worked $h_{t}$ and the real wage $w_{t}$ in the labor supply equation gives:

$$
\chi_{h} y_{t}^{\psi} c_{t}=s_{t}^{\alpha}
$$

For an exogenous rise in consumption, the wealth effect implies that labor supply - and hence production - should fall. However, as mentioned before, the shock is also presumed to raise the relative price of goods, appreciating terms of trade. This would act as a rise in the real wages, producing a substitution effect (hours worked and production up) and a wealth effect (hours worked and production down). In addition, the rise in hours worked and output also conditions the size of the rise in consumption: if labor income increases enough - if the substitution effect dominates, the rise in consumption should be larger since output will increase more. This should also raise terms of trade more. In any case this equation suggests that a joint rise in consumption and terms of trade would be fully consistent with the labor supply condition and more generally the supply-side of the small open

3. The small open economy assumption implies that foreign variables are considered exogenous and constant from the perspective of domestic agents, i.e. $c_{t}^{*}=c^{*}$ and $p_{y^{*}}=p^{*}$.

4. In the budget constraint, the real wage is expressed in unit of consumption goods while the firm values the real wage in units of produced goods. 
economy. Finally, our simple model also sheds light on the determinants of the trade balance and net foreign assets. Starting from the budget constraint, using the fact that $d_{t}$ is constant, that $w_{t}=s_{t}^{\alpha}$ and that $h_{t}=y_{t}$, and substituting the goods market clearing condition:

$$
b_{t}-r_{t}^{*} b_{t-1}=s_{t}^{\alpha} y_{t}-c_{t}=\alpha\left(s_{t}^{\alpha-1} c^{*}-c_{t}\right)
$$

This equation suggests that net foreign assets depend negatively on domestic consumption and terms of trade - remember that $\alpha \leq 1$. An exogenous rise in consumption that would also appreciate terms of trade would generate a trade deficit. The latter then triggers a current account deficit. ${ }^{5}$

Let us now focus on the effects of a fall in the real interest rate $r_{t}^{*}$. Imagine that the country is initially constrained, i.e. $\lambda>0$. The borrowing constraint holds with equality which implies $b<0$, i.e. the country has a negative foreign asset position. The transversality condition requires running a trade surplus initially. The Euler equation also tells us that $\beta r^{*}=\left(1-r^{*} \lambda\right)<1$ that is, households are more impatient in the small open economy than in the rest of the world. Further, the equation for the price of durables gives $\lambda=\left(1-\beta-\chi_{d} c / q\right) / m$ which suggests that $\lambda$ is small. Indeed, $(1-\beta)$ is small and $\chi_{d} c / q<1-\beta$ is required to yield $\lambda>0$. This in turn requires small values of the utility weight $\chi_{d}$ and large prices of durables.

With this in mind, the Euler equation suggests that a fall in the real rate will make current consumption rise compared to foreign consumption. Indeed, because $\lambda$ is relatively small, the effects of a fall of $r_{t}^{*}$ on $r_{t}^{*} /\left(1-r_{t}^{*} \lambda_{t}\right)$ are negative. This should then imply $c_{t}>c_{t+1}$. The overall impact on terms of trade should be negative (terms of trade appreciate) and the impact on the trade balance should be negative (trade deficits arise). Within this simplified model, net foreign asset dynamics are inherently unstable, as there are no mechanisms forcing the adjustment of future consumption to make net foreign assets return to their initial values. Therefore the imbalances produced by the shock will last forever, and net foreign assets should drift away in negative region at the rate $r^{*}$. A natural question arises: how can deteriorating asset positions be consistent with our borrowing constraint? Actually, the latter becomes and remains slack. First, the fall in the real rate loosens the constraint immediately. Second, the

5. In the steady state however, the transversality condition requires that a trade deficit is met with a positive foreign asset position whenever $r^{*}>0$. 
dynamics of consumption contributes to maintain the constraint slack. To see this, let us abstract from expectations for simplicity, and look at the value of $\lambda_{t}$ implied by Equation (4):

$$
\lambda_{t}=m^{-1}\left(\frac{q_{t}-\chi_{d} c_{t}}{q_{t+1}}-\beta \frac{c_{t}}{c_{t+1}}\right)
$$

The rise in current consumption pushes $\lambda_{t}$ to zero ( $\lambda$ was initially small) and the constraint is durably slack. As long as consumption is allowed to grow - that is, if net foreign assets are allowed to be negative for long enough - the constraint will remain slack.

Of course the instability of net foreign assets is a problem in this simple model. One way around this is to assume that the discount factor of households increases along with the fall in the real interest rate. All else equal, a rise in the discount factor depresses consumption. ${ }^{6}$ If discount factors adjust one for one with the real interest rate, the overall impact on consumption and in any relevant variable of the model is close to null. In this case, the Euler equation basically implies a constant dynamics for consumption, up to the dynamics of $\lambda_{t}$. If the timing of changes in the real rate and the discount factor differ, we are left with two possibilities: the discount factor adjusts more quickly or more slowly than the real interest rate. If the discount factor rises more quickly than the real rate, $\beta r_{t}^{*}>1$ implies that households become more patient than the rest of the world. Savings will increase and current consumption fall. As shown above, this will generate a terms of trade depreciation, a trade surplus and a rise in net foreign assets. If the discount factor adjusts more slowly, $\beta r_{t}^{*}<1$ implies that households remain more impatient than the rest of the world for a while, which triggers a rise in consumption, an appreciation of terms of trade along with a trade deficit.

The above analysis shows that a borrowing constraint can rationalize the difference between relatively high subjective real rates - low discount factors - and lower effective rates. Further, it shows that a large fall in the real interest rate can generate a rise in consumption along with external imbalances - an appreciation of terms of trade along with trade deficits. For this dynamics to arise, any potential rise in the discount factor introduced to stabilize the model in the long run has to be much slower than the fall in the real interest rate to generate

6. Endogenous discount factor adjustment have been proposed as means to make net foreign asset positions stationary and "close" small open economy models (see Schmitt-Grohé and Uribe (2003) among others). 
the desired effects. Of course, within a more extended model, the dynamics of investment would matter as well. As will be clear however, a fall in the real interest rate will unambiguously raise private investment, with positive associated effects on production and the supplyside. So the contribution of investment in physical capital to the current account imbalances would be less crucial than that of consumption. In addition, the euro area is better described as a tworegion model, in which richer interdependence - through a common monetary policy set-up for instance - is taken into account. Finally, the dynamics of real interest rates in the euro area before and after the euro should result from a more realistic process through which the steadystate inflation rates partly converge after the inception of the euro.

\section{Full model}

We now extend the above model to a core-periphery model of a monetary union with two regions $i=\{c, p\}$. While the simple model helps build intuition about the main mechanism, our goal is more quantitative in the next sections so we include a variety of bells and whistles usually admitted to help DSGE models fit the data, such as external habit in consumption and housing or investment adjustment costs (see Guerrieri and lacoviello (2017) among many others). The two regions are initially heterogeneous in terms of discount factors $\beta^{i}$, inflation rates $\pi^{i}$ and productivity levels $z^{i}$ and financial markets are incomplete. ${ }^{7}$ In the following individual optimization programs, variables are expressed per capita.

Households. Households derive utility from consumption $c_{t}^{i}$ and a stock of durables $d_{t}^{i}$, both corrected with external habits $\in_{c, d} \in[0,1]$, and derive a disutility from working a fraction $h_{t}^{i}$ of their time. Their lifetime welfare function writes

$$
E_{t}\left\{\sum_{s=t}^{\infty}\left(\beta^{i}\right)^{s} u\left(c_{t}^{i}-\epsilon_{c} c_{t-1}^{i}, d_{t}^{i}-\epsilon_{d} d_{t-1}^{i}, h_{t}^{i}\right)\right\}, \beta^{i}<1
$$

and is maximized with respect to the following budget constraint

$$
c_{t}^{i}+q_{t}^{i} \Delta d_{t}^{i}+x_{t}^{i}+a c_{t}^{i}+b_{t}^{i}=w_{t}^{i} h_{t}^{i}+r_{k t}^{i} k_{t-1}^{i}+\frac{i_{t-1}^{n}}{\pi_{t}^{i}} b_{t-1}^{i}+\varsigma_{t}^{i}-\tau_{t}^{i}
$$

7. If markets were complete and integration perfect, real interest rates would converge to a unique value. Financial transaction costs and the presence of borrowing constraints, coupled with heterogeneous discount factors, allow a differential values in real interest rates. 
where $c_{t}^{i}$ denotes consumption, $q_{t}^{i}$ the relative price of durables in region $i, \Delta$ the first-difference operator, $x_{t}^{i}$ the investment in physical capital and $k_{t}^{i}$ the level of physical capital. Further, $b_{t}^{i}$ is the real amount of nominal bonds issued in the monetary union held by households in region $i$ returning $i_{t}^{n}$ between period $t$ and $t+1$, and $a c_{t}^{i}=\phi_{b}$ $\left(b_{t}^{i}-b_{t-1}^{i}\right)^{2} / 2$ is an adjustment cost paid on bonds. ${ }^{8}$ Variables $w_{t}^{i}$ and $r_{k t}^{i}$ denote the real prices of production factors in region $i$ and $\zeta_{t}^{i}$ is the amount of profits received by households from monopolistic retailers. Last, $\pi_{t}^{i}=p_{t}^{i} / p_{t-1}^{i}$ is the CPI inflation rate in region $i$.

Capital accumulation is subject to investment adjustment costs, and households optimize taking into account the following law of capital accumulation:

$$
k_{t}^{i}=\left(1-\delta_{k}\right) k_{t-1}^{i}+\left(1-\phi_{k}\left(x_{t}^{i} / x_{t-1}^{i}-1\right)^{2} / 2\right) x_{t}^{i}
$$

Finally, following Ferrero (2015), households are also potentially constrained in the expected amount they can borrow from the other region based on the amount of durable goods they can pledge: ${ }^{9}$

$$
-r_{t}^{i} b_{t}^{i} \leq m E_{t}\left\{q_{t+1}^{i} d_{t}^{i}\right\}
$$

where $r_{t}^{i}=E_{t}\left\{i_{t}^{n} / i_{t-1}^{i}\right\}$ is the real interest rate. Household $i$ chooses consumption $c_{t}^{i}$, the stock of durable goods $d_{t}^{i}$, labor supply $h_{t}^{i}$, the stock of capital $k_{t}^{i}$, capital investment $x_{t}^{i}$ and international bonds $b_{t}^{i}$ to maximize welfare (10) subject to constraints (11), (12) and (13). The resulting first-order conditions are:

$$
\begin{gathered}
\frac{u_{d t}^{i}}{u_{c t}^{i}}+E_{t}\left\{m \lambda_{t}^{i} q_{t+1}^{i}+\beta^{i} \frac{u_{c t+1}^{i}}{u_{c t}^{i}} q_{t+1}^{i}\right\}=q_{t}^{i} \\
u_{h t}^{i}+u_{c t}^{i} w_{t}^{i}=0 \\
\beta^{i} E_{t}\left\{\frac{u_{c t+1}^{i}}{u_{c t}^{i}} q_{k t+1}^{i}\left(1-\delta_{k}\right)+r_{k t+1}^{i}\right\}=q_{k t}^{i}
\end{gathered}
$$

8. As in Schmitt-Grohe and Uribe (2003) and as usual in the literature, the transaction costs are symmetric whether households increase or decrease their asset holding. However, the formulation of these costs is a bit unusual since most of the literature assumes that costs depend on the deviation of net foreign assets to their steady-state value. However in our framework we want terminal net foreign assets to be determined endogenously - and not to return to their initial values - to account for the wealth transfers induced by shocks.

9. The formulation of the borrowing constraint is very close to the formulation of Guerrieri and lacoviello (2017), except that it is formulated in expected terms. Our results carry over both formulations of the borrowing constraint. 


$$
\begin{gathered}
q_{k t}^{i}\left(1-\frac{\phi_{k}\left(\gamma_{t}^{i}\right)^{2}}{2}-\phi_{k} \gamma_{t}^{i}\left(1+\gamma_{t}^{i}\right)\right) \\
+\beta^{i} E_{t}\left\{\frac{u_{c t+1}^{i}}{u_{c t}^{i}} \phi_{k} q_{k t+1}^{i} \gamma_{t+1}^{i}\left(1+\gamma_{t+1}^{i}\right)^{2}\right\}=1 \\
\beta^{i} E_{t}\left\{\frac{u_{c t+1}^{i}}{u_{c t}^{i}} \frac{i_{t}^{n}+\pi_{t+1}^{i} \phi_{b}\left(b_{t+1}^{i}-b_{t}^{i}\right)}{\pi_{t+1}^{i}\left(1-i_{t}^{n} \lambda_{t}^{i} / \pi_{t+1}^{i}+\phi_{b}\left(b_{t}^{i}-b_{t-1}^{i}\right)\right)}\right\}=1
\end{gathered}
$$

where $U_{d t}, U_{c t}$, and $U_{h t}$ respectively denote the marginal utilities of consumption, the stock of durables and hours worked. Variable $\lambda_{t}^{i}$ is the Lagrange multiplier associated with the borrowing constraint in region $i$, normalized by the Lagrange multiplier associated to the budget constraint. Variable $q_{k t}^{i}$ is the normalized multiplier associated with the law of motion for capital and $\gamma_{t}^{i}=x_{t}^{i} / x_{t-1}^{i}-1$ is the growth rate of investment. The first equation summarizes the intertemporal tradeoff faced by households when choosing the stock of durable goods: the current marginal cost of durables should equate the marginal gains, made of the marginal utility of durables plus the future marginal utility of holding a durable good today. An additional benefit of holding durable goods is the marginal loosening of the borrowing constraint allowed by holding more collateral. The second equation is a standard labor supply equation. The third and fourth equations respectively determine the dynamics of the shadow price of capital $q_{k t}$ and the growth rate of investment in capital $\gamma_{t}$. The last equation is the Euler equation on international bonds.

Aggregate consumption, investment and adjustment costs bundles are a composite of goods produced in each region:

$$
v_{t}^{i}=\left[\left(1-\alpha^{i}\right)^{\frac{1}{\mu}}\left(v_{c t}^{i}\right)^{\frac{\mu-1}{\mu}}+\left(\alpha^{i}\right)^{\frac{1}{\mu}}\left(v_{p t}^{i}\right)^{\frac{\mu-1}{\mu}}\right]^{\frac{\mu}{\mu-1}}, \text { for } v=\{c, x, a c\}
$$

where $1-\alpha^{i}$ measures the weight of core goods in the bundle of households living in region $i$, and $\mu$ is the trade elasticity. The law of one price holds at the producer level, and CPIs are given by

$$
p_{t}^{i}=\left[\left(1-\alpha^{i}\right) p_{c t}^{1-\mu}+\alpha^{i} p_{p t}^{1-\mu}\right]^{\frac{1}{1-\mu}}
$$


Standard consumption and investment sub-indices are given by

$$
\begin{aligned}
v_{c t}^{i} & =\left[\int_{0}^{1} v_{c t}^{i}(\omega)^{\frac{\theta-1}{\theta}} d \omega\right]^{\frac{\theta}{\theta-1}}, v_{p t}^{i} \\
& =\left[\int_{0}^{1} v_{p t}^{i}(\omega)^{\frac{\theta-1}{\theta}} d \omega\right]^{\frac{\theta}{\theta-1}}, \text { for } v=\{c, x, a c\}
\end{aligned}
$$

where $v_{c t}^{i}\left(v_{p t}^{i}\right.$, respectively) is the consumption/investment of goods produced in the core region (resp. in the periphery) by the representative household of region $i$, and $\theta>1$ is the elasticity of substitution across varieties of final goods. Accordingly, optimal demands of varieties can be expressed as

$$
v_{c t}^{i}(\omega)=\left(1-\alpha^{i}\right)\left[\frac{p_{c t}(\omega)}{p_{c t}}\right]^{-\theta}\left[\frac{p_{c t}}{p_{t}^{i}}\right]^{-\mu} v_{t}^{i}, v_{p t}^{i}(\omega)=\alpha^{i}\left[\frac{p_{p t}(\omega)}{p_{p t}}\right]^{-\theta}\left[\frac{p_{p t}}{p_{t}^{i}}\right]^{-\mu} v_{t}^{i}
$$

Finally, let us define terms of trade as

$$
s_{t}=\frac{p_{p t}}{p_{c t}} .
$$

This definition is meant to be consistent with the definition of the real exchange rate, $s_{t}^{r}=p_{t}^{p} / p_{t}^{c}$. Given this notational convention, an increase of $s_{t}$ denotes an appreciation (respectively depreciation) of terms of trade in the periphery (resp. core), implying an fall (resp. rise) in the competitiveness of goods produced in the periphery (resp. core).

Firms. Firms produce final goods under perfect competition with capital and labor, and sell their output to monopolistic retailers at price $p_{m t}^{i}$. The production function is

$$
y_{t}^{i}=z_{t}^{i}\left(k_{t-1}^{i}\right)^{\iota}\left(h_{t}^{i}\right)^{1-\iota}
$$

and profit maximization yields ${ }^{10}$

$$
\begin{gathered}
\iota \frac{p_{m t}^{i} y_{t}^{i}}{k_{t-1}^{i}}=r_{k t}^{i} \frac{p_{t}^{i}}{p_{i t}} \\
\sum_{t=0}^{\infty}\left(\beta^{i}\right)^{t} u_{c t}^{i} \varsigma_{t}^{i}(j),
\end{gathered}
$$

Retailers face Rotemberg (1982) price adjustment costs with a nonunitary steady-state level of inflation. Retailer $j$ 's problem is to maximize the value of the firm:

10. Real factor prices are expressed in units of consumption goods while producers value them in units of produced goods. Further, note that

$$
\frac{p_{t}^{c}}{p_{c t}}=\left[1-\alpha^{c}+\alpha^{c} s_{t}^{1-\mu}\right]^{\frac{1}{1-\mu}} \text { and } \frac{p_{t}^{p}}{p_{p t}}=\left[\left(1-\alpha^{p}\right) s_{t}^{\mu-1}+\alpha^{p}\right]^{\frac{1}{1-\mu}} \text {. }
$$




$$
\sum_{t=0}^{\infty}\left(\beta^{i}\right)^{t} u_{c t}^{i} S_{t}^{i}(j),
$$

subject to the demand function $y_{t}^{i}(j)$ for variety, and real dividends or profits are given by

$$
\varsigma_{t}^{i}(j)=\left(\frac{p_{i t}(j)}{p_{i t}}-p_{m t}^{i}-\frac{\phi_{\pi}}{2}\left[\frac{p_{i t}(j)}{\pi_{i} p_{i t-1}(j)}-1\right]^{2}\right) y_{t}^{i}(j)
$$

Above, $\pi_{i}$ is the steady-state rate of PPI inflation. Maximization leads to an equation that determines the evolution of PPI inflation over time:

$$
\begin{aligned}
(\theta-1) & +\phi_{\pi} \frac{\pi_{i t}}{\pi_{i}}\left(\frac{\pi_{i t}}{\pi_{i}}-1\right) \\
& -\beta^{i} E_{t}\left(\phi_{\pi} \frac{\pi_{i t+1}}{\pi_{i}}\left[\frac{\pi_{i t+1}}{\pi_{i}}-1\right] \frac{u_{c t+1}^{i} y_{t+1}^{i}}{u_{c t}^{i} y_{t}^{i}}\right)=\theta p_{m t}^{i}
\end{aligned}
$$

Central Bank and governments. The Central Bank controls the union-wide nominal interest rate $i_{t}$. Its variations over time are controlled by a simple Taylor-type rule:

$$
\log \left(i_{t}^{n} / i^{n}\right)=\rho_{i} \log \left(i_{t-1}^{n} / i^{n}\right)+\left(1-\rho_{i}\right) d_{\pi} \log \left(\pi_{t} / \pi\right)
$$

where $\pi_{t}=\left(\pi_{t}^{c}\right)^{N}\left(\pi_{t}^{p}\right)^{1-N}$ is the union-wide inflation rate and $N$ is the relative weight of the core region. In each region, a government purchases local goods and pays for it raising lump-sum taxes:

$$
\varpi_{t}^{i} y_{t}^{i}=\tau_{t}^{i}
$$

where $\varpi_{t}^{c}$ is the share of government consumption in GDP of region $i$ at time $t$.

Clearing and net foreign assets. Market clearing conditions on final goods markets are

$$
\begin{aligned}
& N y_{t}^{c}\left(1-\frac{\phi_{\pi}}{2}\left(\frac{\pi_{c t}}{\pi_{c}}-1\right)^{2}-\varpi_{t}^{c}\right) \\
& =N\left(1-\alpha^{c}\right)\left[1-\alpha^{c}+\alpha^{c} s_{t}^{1-\mu}\right]^{\frac{\mu}{1-\mu}}\left(c_{t}^{c}+x_{t}^{c}+a c_{t}^{c}\right) \\
& \quad+(1-N)\left(1-\alpha^{p}\right)\left[1-\alpha^{p}+\alpha^{p} s_{t}^{1-\mu}\right]^{\frac{\mu}{1-\mu}}\left(c_{t}^{p}+a c_{t}^{p}\right. \\
& (1-N) y_{t}^{p}\left(1-\frac{\phi_{\pi}}{2}\left(\frac{\pi_{p t}}{\pi_{p}}-1\right)^{2}-\varpi_{t}^{p}\right) \\
& \quad=(1-N) \alpha^{p}\left[\left(1-\alpha^{p}\right) s_{t}^{\mu-1}+\alpha^{p}\right]^{\frac{\mu}{1-\mu}}\left(c_{t}^{p}+x_{t}^{p}+a c\right. \\
& \quad+N \alpha^{c}\left[\left(1-\alpha^{c}\right) s_{t}^{\mu-1}+\alpha^{c}\right]^{\frac{\mu}{1-\mu}}\left(c_{t}^{c}+a c_{t}^{c}\right)
\end{aligned}
$$


and the clearing conditions on the markets for durables are:

$$
d_{t}^{i}=1 \text { for } i=\{c, p\}
$$

Since we consider durable goods to be in fixed supply, all changes in the demand for durable goods from households translate in changes in the price of durables. These price variations then affect the borrowing constraint by changing the value (but not the volume) of the collateral.

The consolidation of equilibrium and market clearing conditions with the budget constraints of households and governments yields the following dynamics of net foreign assets in the core region:

where

$$
b_{t}^{c}=\frac{i_{t-1}}{\pi_{t}^{c}} b_{t-1}^{c}+t b_{t}^{c}
$$

$$
\begin{aligned}
& t b_{t}^{c}=\frac{(1-N)}{N}\left(1-\alpha^{p}\right)\left[1-\alpha^{p}+\alpha^{p} s_{t}^{1-\mu}\right]^{\frac{\mu}{1-\mu}}\left(c_{t}^{p}+x_{t}^{p}+a c_{t}^{p}\right) \\
& -\left(1-\left(1-\alpha^{c}\right)\left[1-\alpha^{c}+\alpha^{c} s_{t}^{1-\mu}\right]^{\frac{\mu}{1-\mu}}\right)\left(c_{t}^{c}+x_{t}^{c}+a c_{t}^{c}\right)
\end{aligned}
$$

and the market clearing condition for international bonds writes

$$
N b_{t}^{c}+(1-N) s_{t}^{r} b_{t}^{p}=0
$$

Finally, we define current accounts as the variation of net foreign assets and report them as a percentage of GDP:

$$
\frac{c a_{t}^{i}}{y_{t}^{i}}=\frac{\Delta b_{t}^{i}}{y_{t}^{i}} \text { for } i=\{c, p\}
$$

\section{Calibration and steady state}

Preliminary remarks. Our goal is to understand how euro-area economies responded to the inception of the euro. Again, one of the key characteristics of our economy is heterogeneity in steady-state real interest rates, a feature that is difficult to reconcile with homogeneity in discount factors. With an external borrowing constraint, heterogeneity in discount factors is enough to ensure that the borrowing constraint is biding in the region with low discount factor (and not binding in the other region), as shown below. The utility function is defined as:

$$
\begin{aligned}
& u\left(c_{t}^{i}, c_{t-1}^{i}, d_{t}^{i}, d_{t-1}^{i}, h_{t}^{i}\right) \\
& \quad=\log \left(c_{t}^{i}-\epsilon_{c} c_{t-1}^{i}\right)+\chi_{d}^{i} \log \left(d_{t}^{i}-\epsilon_{d} d_{t-1}^{i}\right)-\chi_{h}^{i} \frac{\left(h_{t}^{i}\right)^{1+\psi}}{1+\psi}
\end{aligned}
$$


Imagine that the core region is a net lender and the periphery borrows enough for the constraint to be binding: $\lambda^{c}=0$ and $\lambda^{p}>0$ implying $b^{p} / p^{p}=-m q^{p}$. A first insight into the underlying reasons why the periphery is constrained is transparent from the steady-state Euler equations on bonds:

$$
\begin{gathered}
\beta^{c} i^{n}=\pi^{c} \\
\beta^{p} i^{n}=\pi^{p}-i^{n} \lambda^{p}
\end{gathered}
$$

For a given value of the nominal interest rate that applies in the monetary union, $\lambda^{p}>0$ requires either $\pi^{p}>\pi^{c}$ and/or $\beta^{p}<\beta^{c}$, i.e. the periphery is constrained if it features a higher steady-state rate of inflation and/or more impatient households compared to the core region. Any difference between the effective and subjective real interest rate pushes households in the periphery to borrow up to the limit. Put differently, a key function of the borrowing constraint is thus to allow one of the region of the monetary union to have a different steadystate level of inflation and a different discount factor, as suggested by the pre-euro data reported in Section 2.

Design. Our economies are initially settled in a steady-state characterized by various types of heterogeneity (discount factors, TFP, size, etc...). We then analyze how euro-area economies transit from one steady state to another. The first steady state is calibrated using pre-euro data or exact data from 1999, and the second steady state is calibrated using post-euro data. More formally, we consider that a first set of driving forces - discount factors, inflation rates, and the nominal interest rate - progressively switch from their pre-euro average values to their post-euro average values according to:

$$
\begin{aligned}
& \beta^{i}=\eta_{t} \beta_{0}^{i}+\left(1-\eta_{t}\right) \beta_{1}^{i} \\
& \pi^{i}=\kappa_{t} \pi_{0}^{i}+\left(1-\kappa_{t}\right) \pi_{1}^{i} \\
& i^{n}=\kappa_{t} i_{0}^{n}+\left(1-\kappa_{t}\right) \pi_{1}^{i}
\end{aligned}
$$

where

$$
\begin{aligned}
& \eta_{t}=\left(1-\rho_{\eta}\right) \eta+\rho_{\eta} \eta_{t-1} \\
& \kappa_{t}=\left(1-\rho_{\kappa}\right) \eta+\rho_{\kappa} \kappa_{t-1}
\end{aligned}
$$

In the initial steady state, we have $\eta=0$. When the euro is introduced, $\eta$ switches to zero, inducing a slow convergence. The speed of convergence in discount factors is governed by $\rho_{\eta}$, while the speed of 
convergence for inflation and interest rates is governed by $\rho_{\kappa}$. A second set of potential driving forces will be considered in the form of productivity and government spending shocks, based on observed values as described below.

Driving forces. Our interest countries are two sub-groups of the euro area 5 years before and after the inception of the euro, i.e. from 1993 to 1999 and then from 1999 to 2016. The respective compositions of the core and peripheric regions are those exposed in Section 2, where the core region represents roughly $n=65 \%$ of the total GDP of the euro area. The model is clearly not build to account properly for the effects of the Great Recession but this will give a sense of how far the model can go without any financial/banking frictions and without sovereign default. Our calibration of driving forces borrows from the numbers reported in Section 2. We consider that the pre-EMU nominal interest rate that prevails is that of the core region between 1993 and 1998 , that is $2.99 \%$ annually and that it went to $3.2 \%$ annually on average after 1999 . In quarterly terms it means $i_{0}=1.0074 \%$ before the euro and $i_{1}=1.0079 \%$ after 1999 . The steady-state annual CPI inflation rates were $1.93 \%$ in the core region and $4.14 \%$ in the periphery before the euro and went respectively to $2.18 \%$ and $2.79 \%$ on average after 1999. Again, in quarterly terms, these numbers imply $\pi_{0}^{c}=1.0048, \pi_{1}^{c}=1.0054, \pi_{0}^{p}=1.0102$ and $\pi_{1}^{p}=1.0069$. In accordance with the steady-state Euler equation of the unconstrained region, we fix the discount factor of the core region to $\beta_{0}^{c}=\pi_{0}^{c} / i_{0}^{n}=0.9974$ and $\beta_{1}^{c}=\pi_{1}^{c} / i_{1}^{n}=0.9975$. For the constrained region, we use the observed (detrended) measure of pre-euro real interest rate and set the discount factor accordingly to $\beta_{0}^{p}=0.9951$. For the post-euro discount factor, we impose $\beta_{1}^{p}=\pi_{1}^{p} / i_{1}^{p}$. The speed of convergence in discount factor is assumed to be very low, as we assume $\rho_{\varphi}=0.99$ while inflation rates and the union-wide nominal interest rate converge at a faster rate $\rho_{\kappa}=0.9$. Regarding productivity, we normalize $z_{0}^{p}=1$ and the relative productivity measure is set to $z_{0}^{c}=1.0943$, a number calculated from the data in $1999 .{ }^{11}$ Using the same data, observed average levels of productivity in 2008 suggest a very weak growth of productivity in the periphery between 1999 and 2016: $z_{1}^{p}=1.0135$ but the low average growth of TFP actually hides a boom-bust cycle of TFP over

11. TFP is measured as the Solow residual and taken from the Long-Term Productivity Database maintained at the Banque de France (see Bergeaud, Cette, and Lecat (2016) for details). The dataset is annual so time series are spline-interpolated to obtain quarterly estimates. 
these years, that will be fully taken into account in the simulations. In the core region, we observe a rather large productivity growth over the same period implying $z_{1}^{c}=1.2547$. Over simulations, observed productivity levels of each region are fed to the model at each period. Using OECD data about government expenditure in consumption goods over GDP, we construct aggregate government spending to GDP ratios for each region and find $\bar{\varpi}_{0}^{c}=0.2144$ and $\bar{\varpi}_{0}^{p}=0.1845$ in 1999 and $\varpi_{1}^{c}=0.2192$ and $\varpi_{1}^{p}=0.1891$ in 2016 . We also feed directly the dynamics of government spending to GDP as exogenous shocks to the model. Figure 2 below reports the dynamics of TFP and shares of government spending in GDP that are fed to the model simulations.

Figure 2. Additional exogenous processes: TFP and share of government spending to GDP
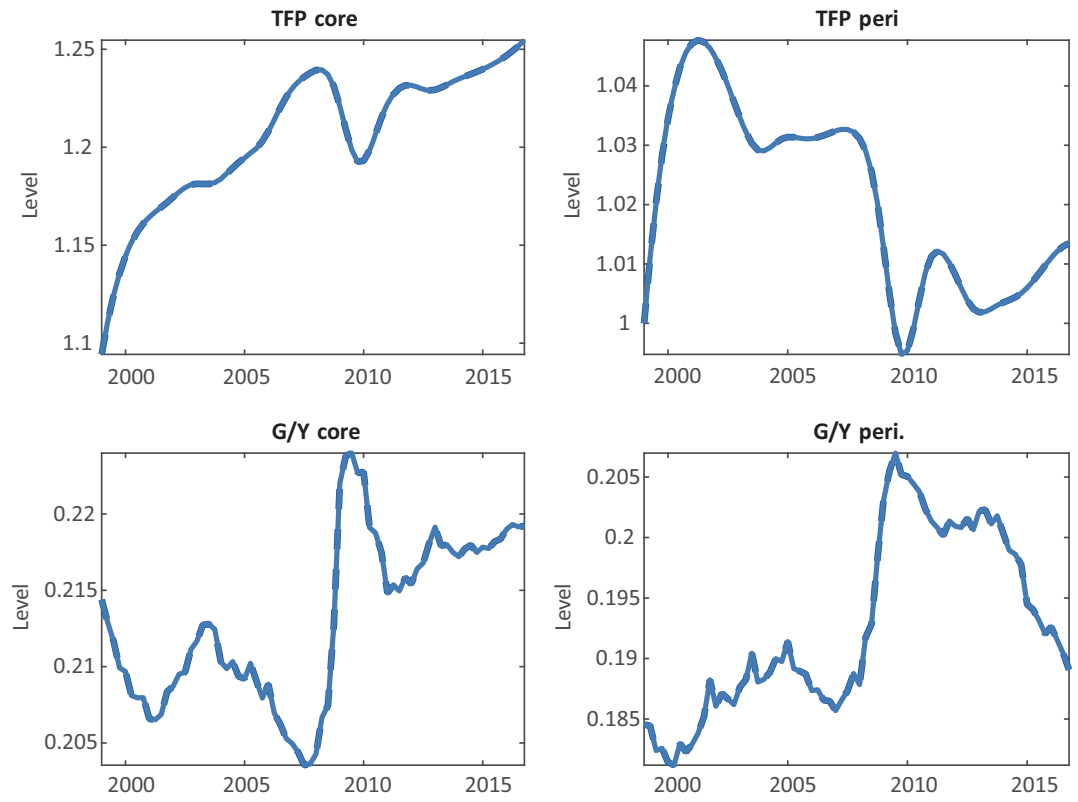

Structural parameters. The remaining parameters are calibrated to relatively standard values: the inverse of the Frisch elasticity is $\psi=0.25$, close to the value chosen by Gertler and Karadi (2011); following Guerrieri and lacoviello (2017), the parameter governing habits in durables is $\epsilon_{d}=0.88$. In addition, the weight of durables in the utility function is adjusted to $\chi_{d}^{c}=0.02$ in the core region, so that the value of the stock of durables is roughly 1.5 times the level of annual GDP. We 
choose $\chi_{d}^{p}=\chi_{d}^{c}=0.02$ and obtain that the price of durables is $17 \%$ higher in the core region than in the periphery in the initial steady state. Given these parameters, we adjust the tightness of the borrowing constraint $m=0.15$ to generate negative net foreign assets in the peripheric region around $20 \%$ of annual GDP - a weighted average calculated on Lane and Milesi-Ferretti (2007)'s data for 1999 suggests that the empirical counterpart was $18 \%$. The parameter governing habits in consumption is $\epsilon_{c}=0.8$, a consensual value in the literature. The labor disutility parameters are adjusted in each region to obtain plausible values of hours worked as a share of total time awake, households working between $30 \%$ and $40 \%$ of the total awake time, and households in the core working less than households in the periphery, as in the data. We calibrate the adjustment cost on foreign bonds to $\phi_{b}=0.0007$ as in Schmitt-Grohe and Uribe (2003). Empirical evidence point to an intra-Eurozone trade openness (total exports plus imports over GDP) of $30 \%$ in 2010 . Adjusting for the share of government consumption - roughly $20 \%$ on average - and assuming symmetry, this implies $\alpha^{c}=1-\alpha^{p}=0.3 \times(1-0.2)=0.24$. The trade elasticity is $\mu=1.5$, as in Auray and Eyquem (2014) and many others. Given the lack of consensus in the literature, a sensitivity analysis will be conducted with respect to this important parameter. In the production sector, we impose an elasticity of output with respect to capital of $l=0.35$, and the capital depreciation rate is adjusted to $\delta_{k}=0.03$ to generate capital-output ratios around 2 in the initial steady state. The investment adjustment cost parameter is chosen in the upper bound but within the set of empirical estimates: $\phi_{k}=5$. The steady-state markup is calibrated to $20 \%$ implying $\phi=6$ and we set $\phi_{\pi}=80$ following Ireland (2001). Finally, the rule followed by the Central Bank is calibrated to standard values. The persistence parameter is $\rho_{\pi}=0.7$ and the response to the union-wide CPI inflation rate is $d_{\pi}=1.5$. Table 1 summarizes the parameter values.

Initial steady state and long run implications. Table 2 reports the initial steady state and the equilibrium values implied by the model after 100 quarters (25 years). The model is solved under perfect foresight by switching $\eta$ from one to zero in the first period and by feeding the observed TFP levels and shares of government spending along the 72 first quarters - that correspond to the scope of our quarterly analysis from 1999 to 2016. The approach is fully non-linear but remains in perfect foresight: except for the very first period, agents know the 
Table 1. Parameter values

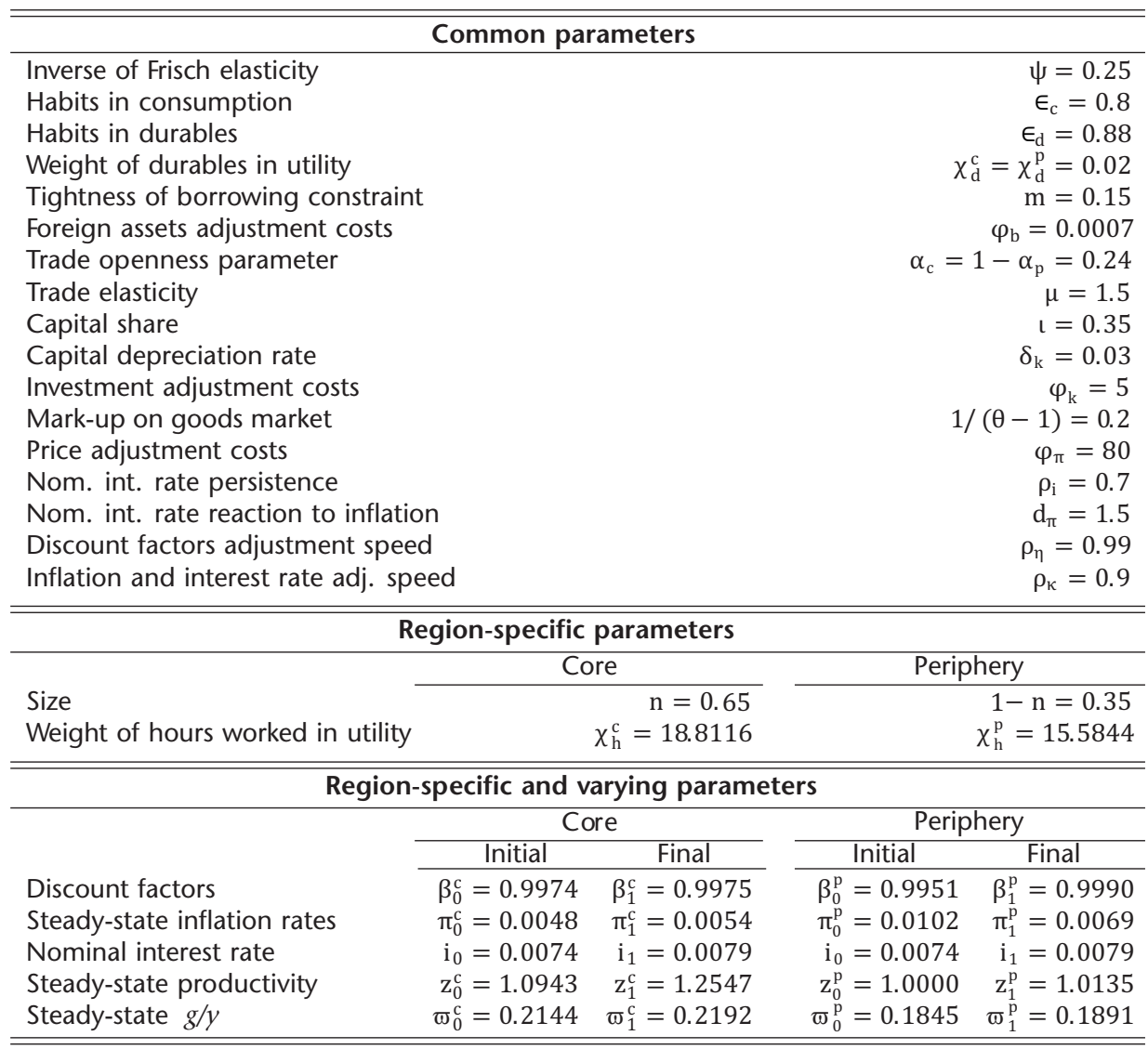

sequence of shocks and driving forces that will occur in the next periods. The algorithm used is a two-point boundary problem using a trust region method. ${ }^{12}$

Starting with the initial steady state, the latter is characterized by the core region being net creditor and the periphery being net debtor and borrowing constrained. As such, the core region has to run a trade deficit and the periphery a trade surplus to sustain their respective net foreign asset positions. Real wages and capital rental rates being larger

12. The routine is implemented through Dynare deterministic simulations set-up (see Adjemian, Bastani, Juillard,Karame, Mihoubi, Perendia, Pfeifer, Ratto, and Villemot, 2011). 
in the periphery initially, the relative price of traded goods is higher there, which is reflected in the fact that the terms of trade are larger than 1. As a consequence, the real exchange (the relative price of goods consumed/invested in the periphery) is also larger than one: the periphery is less competitive than the core region.

Table 2. Initial steady state and equilibrium after 100 quarters

\begin{tabular}{|c|c|c|c|c|}
\hline & \multicolumn{2}{|c|}{ Core } & \multicolumn{2}{|c|}{ Periphery } \\
\hline & Initial & $100 q$ & Initial & $100 q$ \\
\hline Output $(y)$ & 1.2798 & 1.5570 & 1.2924 & 1.4303 \\
\hline Consumption (c/y) & 0.4887 & 0.4845 & 0.6010 & 0.5708 \\
\hline Investment in capital $(c / y)$ & 0.2502 & 0.2497 & 0.2713 & 0.2953 \\
\hline Capital stock $(\mathrm{x} / 4 y)$ & 2.0851 & 2.0380 & 2.2605 & 2.3933 \\
\hline Net foreign assets $(b /(4 y))$ & 0.1285 & 0.6988 & -0.2010 & -1.1762 \\
\hline Real wages $(w)$ & 1.8169 & 2.1962 & 1.9193 & 2.0430 \\
\hline Hours worked $(h)$ & 0.3555 & 0.3549 & 0.3949 & 0.4154 \\
\hline Real rental rates $(w)$ & 0.0326 & 0.0331 & 0.0349 & 0.0334 \\
\hline Borrowing constraint mult. $(\lambda)$ & 0.0000 & 0.0000 & 0.0077 & 0.0000 \\
\hline \multirow[t]{2}{*}{ Current account $(\mathrm{ca} / y)$} & -0.0042 & 0.0344 & 0.0122 & -0.0592 \\
\hline & \multicolumn{2}{|c|}{ Initial } & \multicolumn{2}{|c|}{$100 q$} \\
\hline \multicolumn{5}{|l|}{ Terms of trade $(c / y)$} \\
\hline Real exchange rate $\left(s^{r}\right)$ & & & & \\
\hline
\end{tabular}

Table 2 also shows that the long-run effects of the convergence process are far from neutral in terms of external variables: the long-run terms of trade and real exchange rates are substantially higher than their initial values. In spite of a declining real interest rate and rental rate of capital, the periphery is characterized after the transition by much larger real wages, that contribute to raising the cost of goods produced in this region. In addition, as will be clear in the next Section, the transition is marked by a series of current account deficits in the periphery and a corresponding series of current account surpluses in the core region. These imbalances persist in the medium-long run, as shown by the signs and sizes of trade balances.

If anything, the long run properties of the model imply a relative stability of great ratios (investment and consumption to GDP) in the core region. This is consistent with the relative stability of the capital rental rate and a growth of GDP mainly driven by TFP. Things are quite 
different in the periphery, as the large drop in the rental rate of capital drives a shift of aggregate resources from consumption to investment. Last, the TFP differential in favor of the core also partly explains the longterm persistence in the dynamics of the relative price of traded goods.

\section{Transition}

Baseline simulation. In this section we report the dynamics of variables that result from the convergence process and driving forces described in the previous section. The solution method to solve the transition path non-linearly is also described in the previous Section. Figure 3 below reports the dynamics of key variables of the model both in the core and peripheric regions against the data after 1999.

The dynamics of investment in both regions is very well matched, in particular in the core region, as well as the dynamics of output in the core region. The dynamics of consumption in the periphery is also decently matched overall. Unfortunately, the dynamics of output in the periphery remains relatively lower in the model compared to the data, and consumption does not increase as much as in the data in the core region. In the simulation, the main driving force is a large fall in the real interest rate in the periphery, jointly with a slower increase in the discount factor of households. This set-up triggers a very large increase in private investment, further reinforced in the first half of the sample by the rise in TFP (see Figure 2). In addition, the shock also relaxes the borrowing constraint: households now access foreign bonds without restrictions. The effective rate at which peripheric households borrow is then lower than the slowly decreasing subjective rate. This wedge produces an additional rise in aggregate consumption, that adds-up to the rise in investment. Aggregate demand thus rises substantially in the periphery.

This demand falls mostly on peripheric goods but also on goods produced in the core region, which drives a positive transmission to the core economy. The large rise in aggregate demand in the periphery also puts pressure on the price of local goods: PPI inflation increases in the periphery while not so much in the core region, and terms of trade rise - the relative price of traded goods increases from the perspective of households in the periphery. This rise in terms of trade further strengthens the positive transmission of the shock to the core region, as it produces an expenditure switching effect that diverts part of the 
aggregate demand within the area towards goods produced in the core region. Overall, GDP increases more in the core region while demand is less stimulated, and the reverse occurs in the periphery: a large increase in demand while GDP displays a more sluggish dynamics. As a result, a persistent current surplus is observed in the core region and an equivalently persistent current account deficit develops in the periphery.

Figure 3. Transition after the inception of the euro.
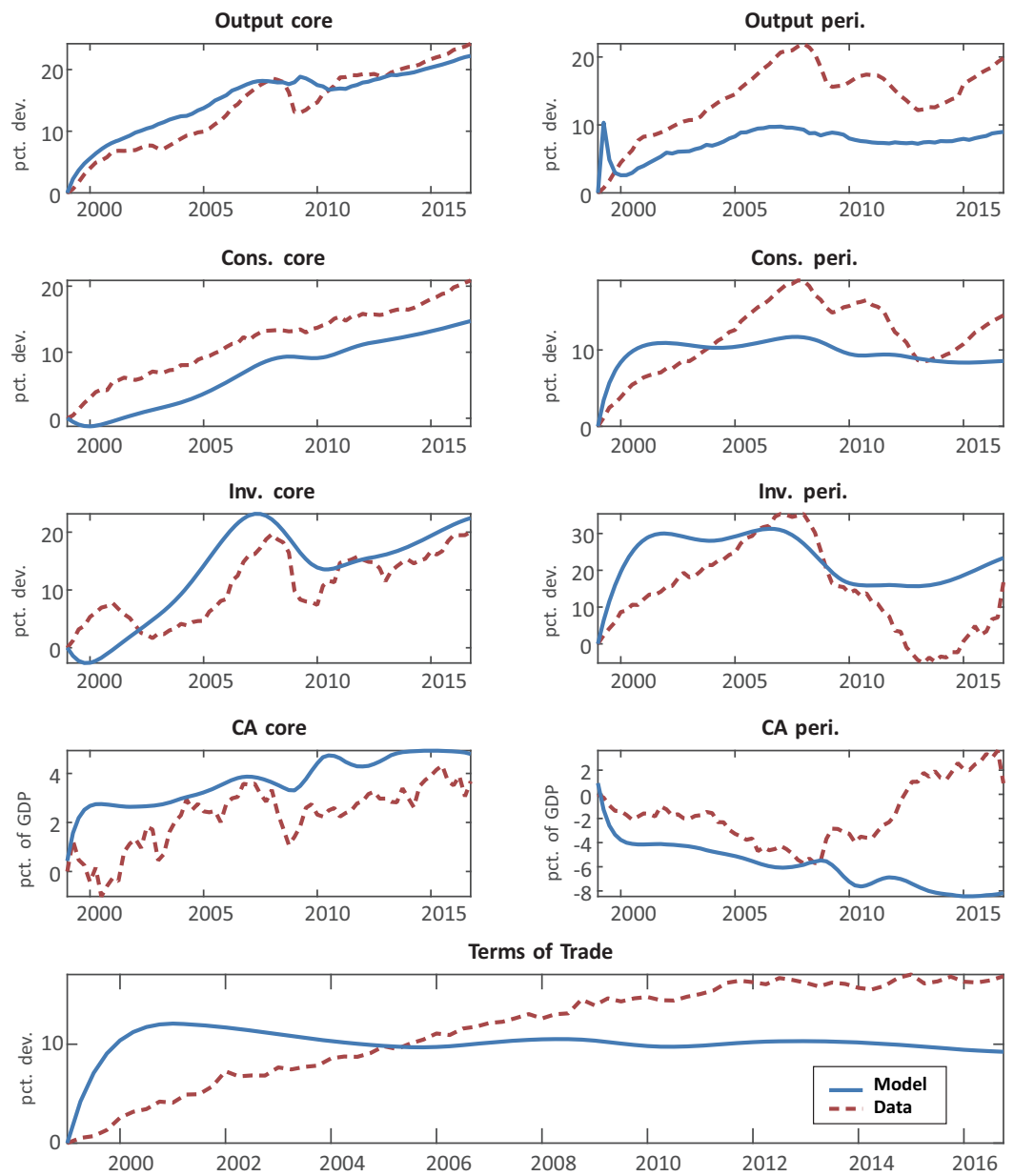

Solid: model. Dashed blue: data. CA denotes the Current Account. 
Quantitatively, the fact that the model tends to predict a more sluggish dynamics of output in the periphery and consumption in the core region produces current account dynamics that are larger than observed. However, the overall pattern predicted by the model is clearly consistent with the data. In addition, the dynamics of terms of trade is also quite well matched: the latter appreciate by roughly $10 \%$ over the sample but peak at $12 \%-17 \%$ in the data. While the model performs globally well in matching the data, especially for the core region and for external variables, one can be curious about the respective contributions of the convergence process and the additional driving forces (TFP and government spending shocks).

Decomposition. Figure 4 below performs the same simulation of the model but offers a decomposition of the effects at play. A simulation is first conducted abstracting from the additional set of TFP and government spending shocks. Then we add TFP shocks but ignore government spending shocks. Finally, we add government spending shocks and abstract from TFP shocks.

Figure 4 clearly shows that the bulk of post-euro fluctuations are relatively well accounted for without any additional shocks, at least qualitatively. In this case, the model predicts a counterfactually large boom in core GDP and a counterfactually small boom in peripheric GDP. This tends to produce quite larger fluctuations in current accounts but otherwise the fit is qualitatively satisfactory. Overall, a very simple convergence process made of partial convergence in inflation rates and the relaxing of a borrowing constraint allowing households to access lower real interest rates in the periphery does a decent job in explaining the observed post-euro external imbalances.

Among the additional shocks considered, Figure 4 also shows that only TFP has a significant impact on the dynamics of key variables. The contribution of government spending shocks is minor. TFP shocks moderate the rise in macroeconomic aggregates in the core region: GDP, consumption and investment all rise less, producing substantially lower external surpluses therefore requiring less adjustments in terms of trade. Interestingly enough, the dynamics of government spending to GDP ratios does not play any significant role in our model and does not contribute in any way to the dynamics of imbalances or other key macroeconomic variables. The fiscal explanation of external imbalances does not seem to receive much support, at least within the scope of our model. 
Figure 4. Decomposition of the effects
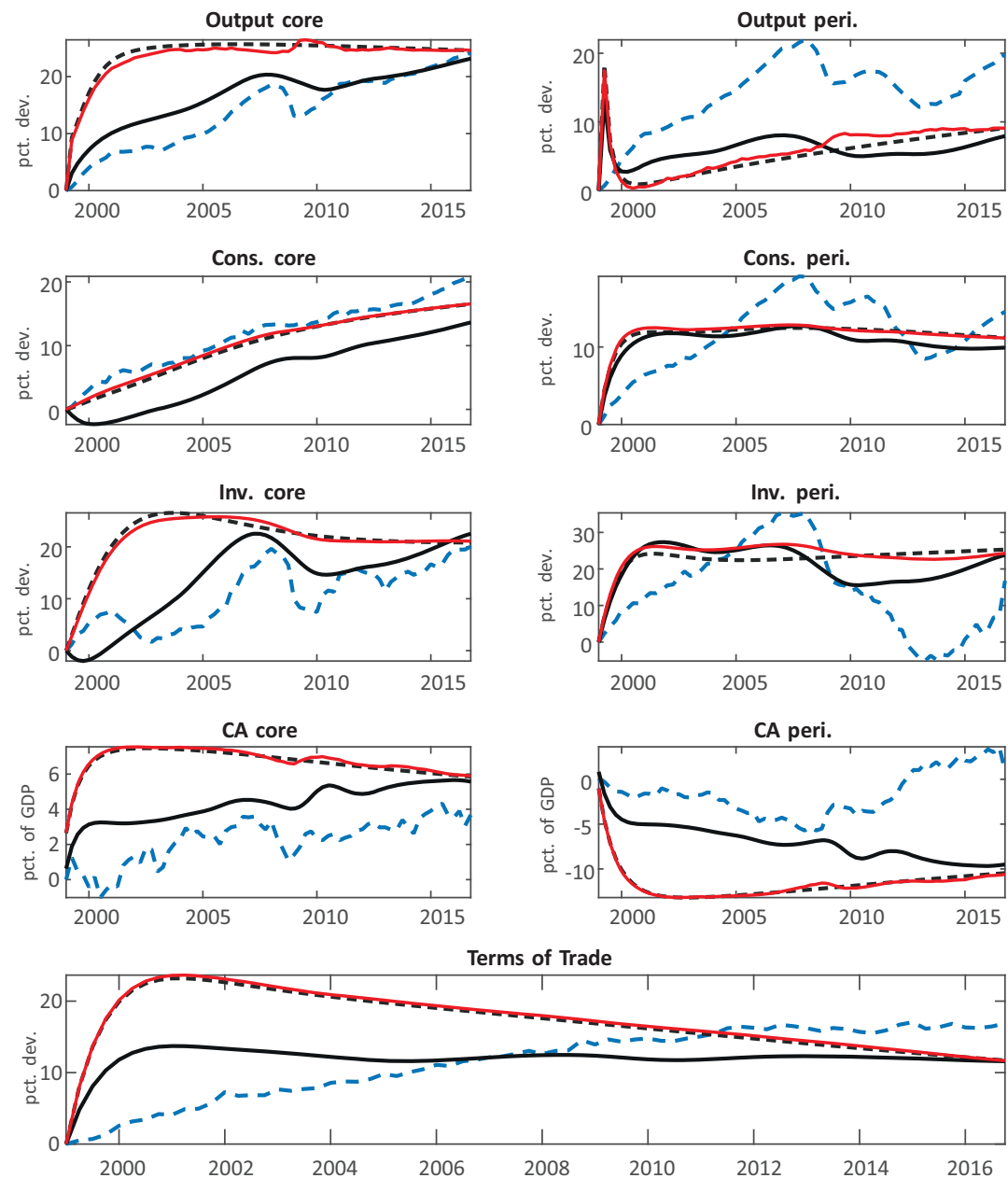

Dashed blue: data. Dashed-dotted black: Transition only (No TFP and GS shocks). Solid black: Transition + TFP shocks. Solid red: Transition + GS shocks. Transition: slow change in steady-state inflation rates, nominal interest rate and discount factors.

The above decomposition thus shows that ex-ante heterogeneity and the convergence process leading the real interest too fall in the periphery can be sufficient to account qualitatively for the imbalances observed in the euro area after the inception of the euro. It can also account for a substantial share of the dynamics of GDP, investment and consumption, especially in the core region. Introducing TFP shocks helps improve the quantitative fit of some key variables, and government spending shocks are basically neutral. 
Full inflation convergence. We now use our model to answer the following question: what would have been the result, especially in terms of external variables, of a more complete inflation convergence process? Indeed, our calibration features a relatively stable rate of inflation in the core region and a fall in the steady-state level of inflation in the periphery. But this fall is limited - from $4.14 \%$ to $2.79 \%$ annually which contributes to lower the post-euro real rate and raise the size of the associated discount factor change. What if inflation fell in the periphery from $4.14 \%$ annually to $2.18 \%$ instead of falling only to $2.79 \%$ as in the baseline scenario? The corresponding post-euro real interest rate would have been $1 \%$ instead of only $0.42 \%$. Figure 5 below reports the resulting dynamics of a full convergence in inflation rates.

Figure 5. Full convergence in steady-state inflation rates


Inv. peri.
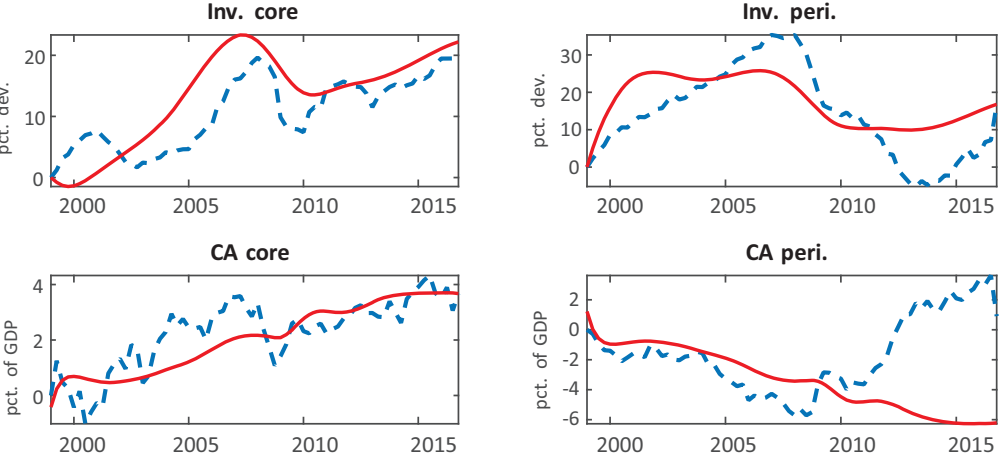

CA peri.
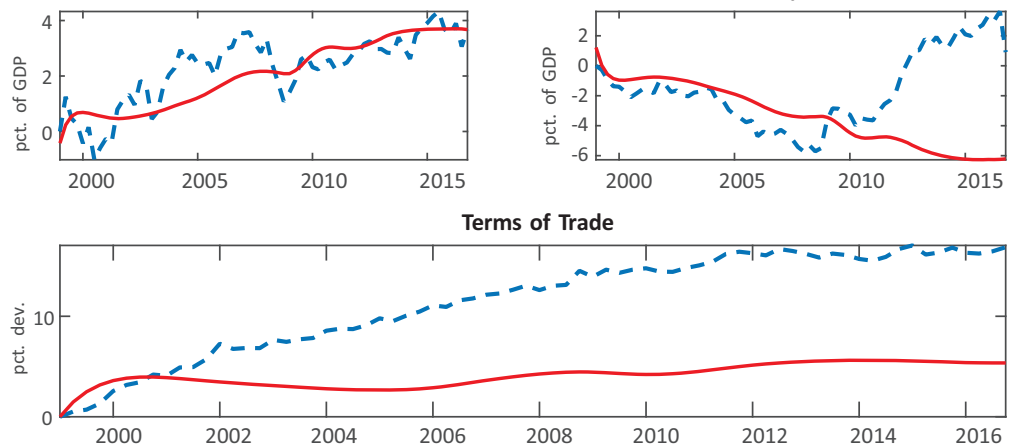

Dashed blue: data. Solid: model. 
As expected, Figure 5 shows that a full convergence in inflation rates dampens the relative importance of the real interest rate shock: the boom in the periphery is now very much contained. Private consumption remains almost flat and investment is booming less. As a result, because aggregate demand is less stimulated in the periphery, terms of trade are now almost unresponsive. The signs of current account imbalances are preserved but their magnitudes are dramatically reduced. Last but not least, the relative importance of TFP dynamics in shaping the fluctuations in both regions is now magnified, especially in the core region. From this counterfactual experiment, we conclude that a complete convergence process of inflation rates would have seriously reduced the size of euro area imbalances, by reducing the size of the swing in the real rate experienced by the periphery. The partial nature of convergence in inflation rates thus happens to be an important driver of the observed imbalances.

\section{Sensitivity analysis}

We investigate the robustness of our results to various changes in parameters. We decide to report the sensitivity of our results with respect to parameters whose value is potentially controversial in the literature. This would typically be the case of the trade elasticity $\mu$ and the inverse of the Frisch elasticity $\psi$. In addition, some parameters are of great importance in determining the sign and size of our results. For instance we expect the portfolio costs parameter to be important, as it governs the adjustment pattern of consumption, and therefore to the size of current account imbalances. Another critical parameter is the adjustment speed of the discount factor, that greatly determines the wedge between the effective and subjective real interest rate in the periphery (see Section 3 for a discussion within the scope of our simple model). Figure 6 reports the dynamics of external variables (current account balances to GDP and terms of trade) when varying those four key parameters.

As made clear by the first row of Figure 6 . We vary $\phi_{b}$ between the baseline value $\phi_{b}=0.0007$ used by Schmitt-Grohé and Uribe (2003) and $\phi_{b}=0.0002$, a value close to the value used by Ghironi and Melitz (2005). Obviously the size of adjustment costs on net foreign assets are of quantitative but not qualitative importance. Larger costs paid on net foreign assets induce larger effects of realized external imbalances on 
Figure 6. Sensitivity analysis

Foreign assets adjustment cost $\left(\varphi_{b}\right)$

(a) CA core

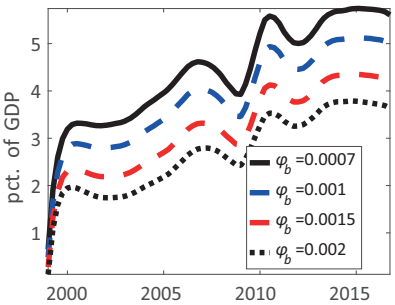

(d) CA core

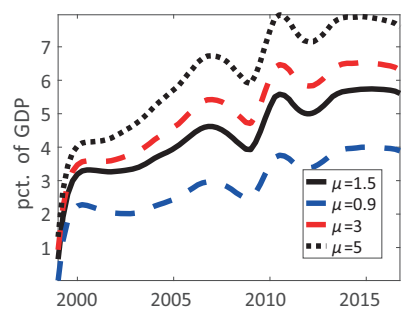

(g) CA core

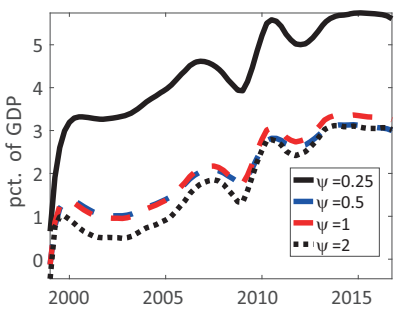

(b) CA peri.

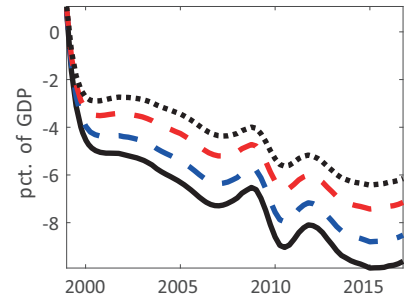

Trade elasticity $(\mu)$

(e) CA peri.

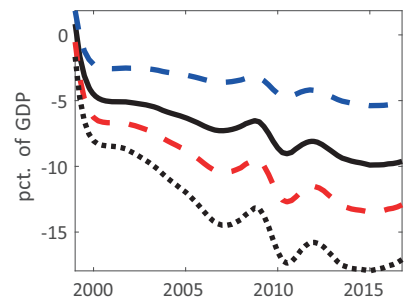

Inverse of Frisch elasticity $(\psi)$

(h) CA peri.

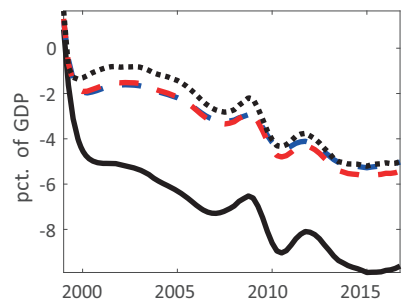

(c) Terms oftrade

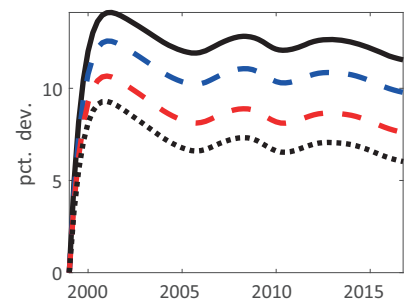

(f) Terms oftrade

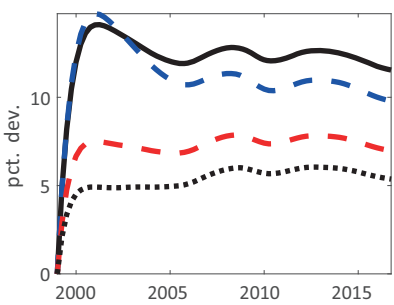

Speed of discountfactor adjustment $\left(\rho_{\eta}\right)$

(j) CA core

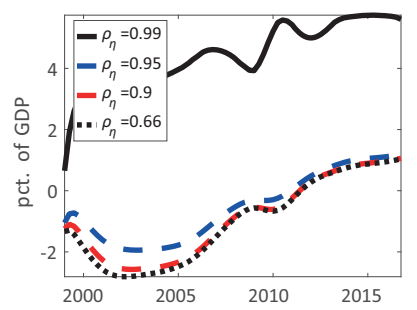

(k) CA peri.

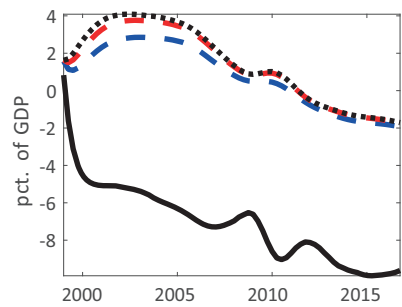

(i) Terms oftrade

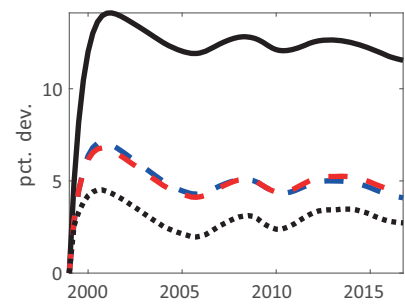

Solid black: baseline calibration

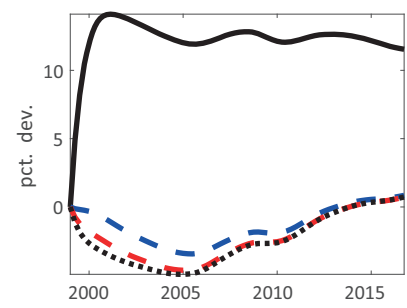


real rates and therefore consumption dynamics, implying smaller current account deficits and dampened fluctuations in terms of trade. The qualitative result according to which the transition is characterized by current account surpluses in the core region and deficits in the periphery is preserved in any case. So is the appreciation of terms of trade.

Similarly, the effects of the trade elasticity $\mu$ are essentially quantitative. Varying this parameter from below unity $\mu=0.9$ to much larger values such as $\mu=5$ - as suggested by the literature in trade - only impacts the size of terms of trade and current account dynamics. A higher (resp. lower) trade elasticity requires less (resp. more) movements in terms of trade to trigger larger (resp. smaller) movements in quantities, which is exactly what shows the second row of Figure 6. Recent discussions about the size of exchange rate pass-through and expenditure-switching effects highlight that producer currency pricing implies counterfactually high elasticities of imported and exported quantities with respect to relative prices (see the discussions in Burstein and Gopinath (2014) for instance). This would comfort our choice of using a relatively small trade elasticity.

The next important parameter is the inverse of the Frisch elasticity $1 / \psi$. We vary the elasticity of labor supply between our benchmark value $1 / \psi=4$ taken from Gertler and Karadi (2011), which arguably lies at the upper bound of existing values, and a much smaller value of $1 / \psi=0.5$. Our model predicts that the real wage and hours worked increase in both countries - labor demand increases more than supply. As such, the slope of the labor supply curves, that depends on the Frisch elasticity, is critical. When the Frisch elasticity is small ( $\psi$ large), the substitution effect - hours worked rise along with real wages - is more easily dominated by the wealth effect - hours worked fall with rising consumption. This lesser rise in hours worked translates into less labor income and therefore less rise in consumption. In the core country, this effect is more than compensated by the dynamics of terms of trade - local goods become relatively cheaper - while the smaller rise in consumption is reinforced by the dynamics of terms of trade in the periphery. Overall, when $\psi$ is large, consumption rises more in the core region and less in the periphery, which dampens the fluctuations of current account balances and terms of trade. Our model thus needs a relatively large elasticity of labor supply ( $\psi$ small) to match the observed dynamics of current accounts in the euro-area. 
Last but not least the parameter governing the adjustment speed of the discount factor in the periphery $\rho_{\eta}$ has important qualitative and quantitative implications. Lower values of this parameter actually reverse our main result. The chief reason is that for investment and consumption - aggregate demand - to rise a lot in the periphery, the model needs to produce a very persistent wedge between the effective real interest rate and the subjective real interest rate. Indeed, consumption is a forward variable that reacts to the long-term real interest rate. Whenever the wedge between subjective and effective real rates closes too fast, only investment is stimulated while consumption is depressed or remains flat. If consumption drops or remains flat in the periphery instead of rising, the changes in aggregate demand produce opposite variations in the terms of trade - they depreciate - which in turn stimulates production there and depresses production in the core region (relative to our baseline calibration). Overall, the assumption of a very slow convergence in discount factor is critical to generate empirically plausible dynamics.

\section{Conclusion}

This paper suggests that the reversal in real interest rates observed after the inception of the euro is critical in generating the post-euro current account imbalances and relative price dynamics. We introduce a borrowing constraint that initially binds in the periphery to account for the heterogeneity in (subjective) real rates before the euro, and model the inception of the euro as a partial convergence process in inflation rates. In the long-run, the discount factor of agents in the periphery is also adjusted to guarantee that the model remains stable. This simple set of driving forces already goes a long way in explaining the current account imbalances and terms of trade dynamics. This large positive demand shock in the periphery puts pressure on relative prices produced there, and the massive boom in consumption and investment generate the current account deficits. Other shocks (government spending in particular) have relatively minor consequences compared to this main driving force. Had the convergence process in inflation rates been complete, the resulting imbalances would have been dampened, and the dynamics of relative prices would have remained almost flat. 
While we do not conclude from our experiments that our explanation dominates alternative explanation for these imbalances. We rather see our explanation as an interesting complement. One key implication of our work here is that, if the imbalances result from this simple dynamics of real rates, then they are not to be imputed to the governments of euro area countries directly, traced to a set of identified policy decisions, or resulting from any kind of "original sin". Better cooperation in the form of transfers could have mitigated them; cooperation might be necessary in the future to close them, but there is not an identified responsibility in the genesis of these imbalances. They might simply reflect the design of the euro area as an area of low nominal rates and slowly converging inflation rates.

\section{References}

Adjemian, Stéphane, Houtan Bastani, Michel Juillard, Frédéric Karamé, Ferhat Mihoubi, George Perendia, Johannes Pfeifer, Marco Ratto, and Sébastien Villemot. 2011. "Dynare: Reference Manual, Version 4." Dynare Working Papers 1, CEPREMAP.

Auray, Stéphane and Aurélien Eyquem. 2014. "Welfare Reversals in a Monetary Union." American Economic Journal: Macroeconomics 6 (4): 246-290.

Bergeaud, Antoine, Gilbert Cette, and Rémi Lecat. 2016. "Productivity Trends in Advanced Countries between 1890 and 2012." Review of Income and Wealth 62 (3): 420-444.

Blanchard, Olivier and Francesco Giavazzi. 2002. "Current Account Deficits in the Euro Area: The End of the Feldstein Horioka Puzzle?" Brookings Papers on Economic Activity 33 (2): 147- 210.

Burstein, Ariel and Gita Gopinath. 2014. "International Prices and Exchange Rates." In Hand- book of International Economics, Handbook of International Economics, vol. 4, edited by Gita Gopinath, Elhanan Helpman, and Kenneth Rogoff. Elsevier, 391-451.

Chen, Ruo, Gian Maria Milesi-Ferretti, and Thierry Tressel. 2012. "External Imbalances in the Euro Area." IMF Working Paper 12/236.

Ferrero, Andrea. 2015. "House Price Booms, Current Account Deficits, and Low Interest Rates." Journal of Money, Credit and Banking 47 (S1): 261-293.

Gertler, Mark and Peter Karadi. 2011. "A Model of Unconventional Monetary Policy." Journal of Monetary Economics 58 (1): 17-34. 
Ghironi, Fabio and Marc J. Melitz. 2005. "International Trade and Macroeconomic Dynamics with Heterogeneous Firms." Quarterly Journal of Economics 120 (3): 865-915.

Gopinath, Gita, Şebnem Kalemli-Özcan, Loukas Karabarbounis, and Carolina Villegas-Sanchez. 2017. "Capital Allocation and Productivity in South Europe." The Quarterly Journal of Economics 132 (4): 1915-1967.

Guerrieri, Luca and Matteo Iacoviello. 2017. "Collateral Constraints and Macroeconomic Asymmetries." Journal of Monetary Economics 90 (1): 28-49.

Ireland, Peter N. 2001. "Sticky-price Models of the Business Cycle: Specification and Stability." Journal of Monetary Economics 47: 3-18.

Lane, Philip R. and Gian Maria Milesi-Ferretti. 2007. "The External Wealth of Nations Mark II: Revised and Extended Estimates of Foreign Assets and Liabilities, 1970-2004." Journal of International Economics 73: 223-250.

Lourenço, Rita and Paulo M.M. Rodrigues. 2015. "House Prices: Bubbles, Exuberance or Some- thing Else? Evidence from Euro Area Countries." Working Papers 2015-17, Banco de Portugal, Economics and Research Department.

Ozhan, Galip Kemal. 2020. "Financial Intermediation, Resource Allocation, and Macroeconomic Interdependence." Journal of Monetary Economics 115 (C): 265-278.

Rotemberg, Julio J. 1982. "Monopolistic Price Adjustment and Aggregate Output." Review of Economic Studies 49 (4): 517-531.

Rubio, Margarita. 2018. "National Macroprudential Policies in the Euro Area: Flexibility vs. Supervision." Economics Letters 170 (C): 55-58.

Schmitt-Grohé, Stephanie and Martín Uribe. 2003. "Closing Small Open Economy Models." Journal of International Economics 61 (1): 163-185.

Siena, Daniele. 2021. "The Euro Area Periphery and Imbalances: Is it an Anticipation Story?" Review of Economic Dynamics 40: 278-308.

Sy, Mouhamadou. 2016. "Overborrowing and Balance of Payments Imbalances in a Monetary Union." Review of International Economics 24 (1): 67-98. 


\section{APPENDIX}

\section{Data description and sources}

\section{Euro area}

- Countries: Austria, Belgium, Finland, France, Germany, Ireland, Italy, Netherlands, Portugal, Spain.

- Gross Domestic Product: Real GDP in volume at market prices, in euros. Quarterly time series from 1992Q1 to 2016Q4. Source: OECD Economic Outlook 101.

- Nominal interest rate: Short-term nominal interest rate, in percents. Quarterly time series from 1992Q1 to 2016Q4. Source: OECD Economic Outlook 101.

- GDP deflator: Price index at market prices $(100=2010)$. Quarterly time series from 1992Q1 to 2016Q4. Source: OECD Economic Outlook 101.

- PPI inflation rate: Computed as the 4-quarters difference in GDP deflator, in percents. Quarterly time series from 1993Q1 to 2016 Q4.

- Consumption: Real private final consumption expenditure, in euros. Quarterly time series from 1999Q1 to 2016Q4. Source: OECD Economic Outlook 101.

- Investment: Real gross fixed capital formation, in euros. Quarterly time series from 1999Q1 to 2016Q4. Source: OECD Economic Outlook 101.

- Current account: Current account balance as a percentage of GDP. Quarterly time series from 1999Q1 to 2016Q4. Source: OECD Economic Outlook 101.

- Terms of trade: Relative price of traded goods, index $(100=2010)$. Quarterly time series from 1999Q1 to 2016Q4. Source: OECD Economic Outlook 101.

- Government spending: Real general government final consumption expenditure, as a percentage of real GDP. Quarterly time series from 1999Q1 to 2016Q4. Source: OECD Quarterly National Accounts. 
- Total factor productivity: Solow residual from a constant return to scale Cobb-Douglas production function with capital stock and hours worked as input. Missing data for Ireland. Annual time series from 1993 to 2016 (spline-interpolated to quarterly frequency). Source: Long-term Productivity database (http:// www.longtermproductivity.com/about.html).

- Net foreign assets: net foreign assets as a percentage of GDP. Annual time series from 1999 to 2011. Source: Lane and MilesiFerretti (http://www.philiplane.org/EWN.html).

\section{United States}

- Nominal interest rate: Effective federal funds rate, in percents (FEDFUNDS). Quarterly time series from 1993Q1 to 2016Q4. Source: Federal Reserve Economic Data.

- CPI index: Consumer price index for all urban consumers: all Items, percent change from year ago (CPIAUCSL_PC1). Quarterly time series from 1993Q1 to 2016Q4. Source: Federal Reserve Economic Data. 